\title{
"Grow": The Art of Community Art Engagement
}

The collaborative art piece titled "Grow," featured on the cover of the current Journal Issue, was originally created for and launched at the conference "Quality of Life: Towards Sustainable Community Futures," hosted by the Community-University Institute for Social Research (CUISR) at the University of Saskatchewan on May 15-16, 2014. This artistic expression created by April Doepker, Emily Krueckl, Di Decaire, Silano Shamo, Jerry Potié, Andy Zimmerman, Jane McWhirter, and Tammy Krueckl reflects on the theme of the conference and factors that are foundational to quality of life.

The artists who created the cover image are involved with the well-known communitybased organization, Saskatoon Community Youth Arts Programming (SCYAP) Inc. SCYAP is a charitable organization that meets the social, educational, and economic needs of youth at-risk through arts and culture. It was established in 2001 to offer street-level, youth-oriented solutions to crime and unemployment by using an interest in visual art as the key to personal development and redirection towards a healthier and more productive life. SCYAP (conveniently located in Saskatoon's downtown) offers a variety of art programs and community art initiatives with the purpose of giving youth the opportunity to make a connection with the wider community and earn the recognition and confidence that comes with it.

To highlight the accomplishments of this unique organization, the Journal is reprinting here an article by Michael Robin, first published in the University of Saskatchewan's On Campus News, August 28, 2015. It tells the story of the growth and journey of one SCYAP artist: Jane McWhirter.

We gratefully acknowledge permission to reprint the article by Michael Robin here in the special issue. 